\title{
AFSCHRIJVINGEN BIJ GESTEGEN PRIJSNIVEAU
}

\author{
door Drs. L. van Kampen Jr.
}

Over het onderwerp van dit opstel is in dit tijdschrift reeds eerder gepubliceerd en wel in 1949 door S. A. de Vries en in 1950 door L. F. Ras.

De aanleiding dat wij op het onderwerp terugkomen is dat in de commissie voor het afnemen van het examen Voortgezet Boekhouden bij het N.I.v.A. meningsverschil was gerezen naar aanleiding van een vraagstuk, waarin gevraagd werd naar de wijze van boeking van afschrijvingen bij stijgend prijsniveau. Hierbij bleek dat de kwestie nog niet afdoende is belicht en dat de behandeling onvolledig is geweest.

Wij zullen trachten hier een bijdrage te leveren tot aanvulling van het gebleken hiaat. Helaas kunnen wij daarbij niet vermijden soms te herhalen wat anderen eerder naar voren hebben gebracht.

Wijlen Nico J. Polak heeft destijds, voorzover ons bekend als eerste, erop gewezen dat onder bepaalde omstandigheden een combinatie van een aantal werktuigen of andere vaste activa, b.v. schepen, een voorraad werkeenheden bevat, hetwelk slechts weinig meer is dan de helft van de som der voorraden werkeenheden van de nieuwe werktuigen ${ }^{1}$ ).

Volledigheidshalve volgt hieronder een schema, hetwelk de stelling verduidelijkt

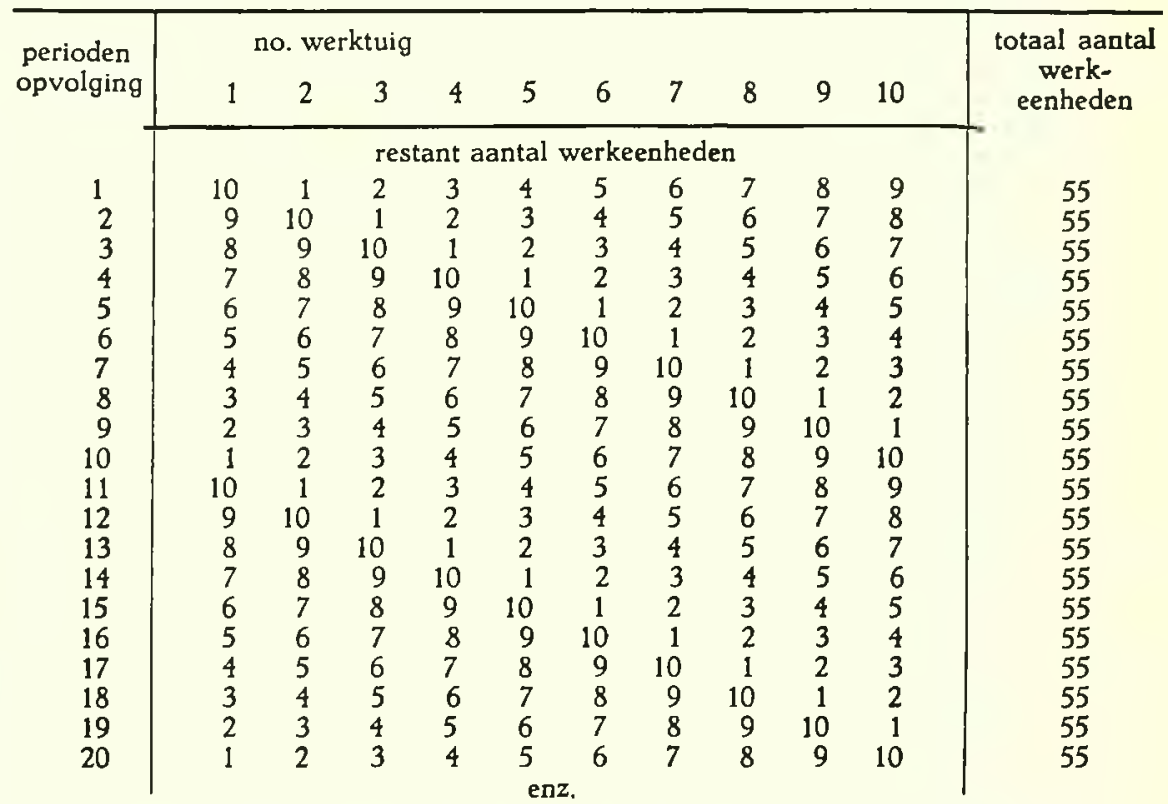

Ter toelichting bij deze staat het volgende. Er zijn tien werktuigen, die in opeenvolgende perioden moeten worden geremplaceerd naarmate zij de in zich geincorporeerde werkeenheden hebben afgestaan. In elke periode geeft een werktuig een van zijn 10 werkeenheden af. De tien aanwezige werktuigen geven tezamen tien werkeenheden af. Tegenover deze afge-

1) In de laatste tijd heeft dit verschijnsel in Duitsland de belangstelling onder de benaming "Lohman Effekt". 
geven werkeenheden vloeit aan het bedrijf een zeker schijninkomen 2 ) toe, welks hoogte afhankelijk is van het op dat moment heersende prijsniveau. Dit schijninkomen ligt onder de klem der vervangingsverplichting. Deze vervanging heeft plaats door het aanschaffen van een nieuw werktuig, hetwelk technisch in de plaats treedt van het werktuig, hetwelk juist zijn laatste werkeenheid heeft afgegeven.

Het schema geeft weer het restant aantal in de werktuigen geïncorporeerde werkeenheden.

Het totaal van het in het bedrijf aanwezige werkeenheden blijft steeds gelijk en wel 55. Dit is de vaste stock, een soort ijzeren voorraad, hetwelk het symbool is van de realisatie van de vervangingsverplichting. Bij de ruil komt de tegenwaarde van de tien afgestane werkeenheden als schijninkomen in het bedrijf en op hetzelfde ogenblik worden tien nieuwe werkeenheden in de vorm van een nieuw werktuig aangetrokken.

De totale stock aan werkeenheden is 55 , hetgeen iets meer is dan de helft van het totaal in tien nieuwe werktuigen geincorporeerde aantal hetwelk vanzelfsprekend honderd is. In feite is het $10 \%$ meer. Het percentage is afhankelijk van het aantal perioden waarin het werktuig zijn werkeenheden afstaat. Waren er b.v. twintig werktuigen, die hun werkeenheden in 20 perioden afstaan dan waren er in totaal 210 werkeenheden tegenover 400 in 20 nieuwe werktuigen of $5 \%$ meer dan de helft. Bij 30 werktuigen is het overeenkomstige percentage $31 / 3 \%$ enz.

Een werktuigenpark hetwelk is opgebouwd naar het geschetste schema wordt genoemd een "harmonisch opgebouwd machinepark" (S. A. de Vries), of een ,ideaal complex duurzame productiemiddelen" (B. Pruyt) ${ }^{3}$ ). Wij kunnen ook spreken van ideale diversiteit of harmonische diversiteit.

De voordelen van een dergelijke harmonische diversiteit liggen voor de hand. Het benodigde vermogen voor een bepaalde productiecapaciteit is slechts ruim de helft van dat benodigd indien men met uitsluitend nieuwe werktuigen werkt. De kosten van het aantrekken van vermogen komen dus op lager niveau. Het economisch motief zal de bedrijven, bewust of onbewust, tot de toepassing van de harmonische diversiteit drijven. Dit wordt vergemakkelijkt door het feit dat de harmonische diversiteit niet gebonden is aan werktuigen van gelijke soort, zoals in het voorbeeld voor de eenvoudigheid van de voorstelling is verondersteld en ook niet tot werktuigen van gelijke levensduur. Men kan zich b.v. voorstellen dat de tien kolommen in het schema tien verschillende afdelingen voorstellen. Elke afdeling draagt bij tot het gezamenlijke schijninkomen benodigd om in een periode één der afdelingen te vernieuwen. In een volgende periode wordt een volgende afdeling uit het gezamenlijke schijninkomen vernieuwd. Het wezenlijke is dat het schijninkomen onmiddellijk voor vervanging wordt gebruikt en dat het totaal aantal werkeenheden in het bedrijf op peil blijft.

Zuinigheid in vermogensaanwending is een van de factoren die de bedrijven, indien zij daartoe althans technisch de kans krijgen, tot de harmonische diversiteit drijven. Met die zuinigheid in vermogensaanwending hangt nog een ander voordeel samen, en wel dat door het vermijden van overtollig vermogen, verliezen welke haar oorzaak in de geldsfeer vinden,

2) De term "schijninkomen" is afkomstig van Nico J. Polak, en wordt met instemming gebruikt door S. Kleerekoper in zijn .Bedrijfseconomie". Het is een uitdrukking voor de aan een bedrijf toekomende tegenwaarde voor afgestoten werkeenheden. Limperg gebruikt het woord schijninkomen in andere betekenis. Zie 25 jaren M.A.B. 1 pag. 341.

3) Diesrede op 8 November 1954.

* Voor nadere uiteenzetting van dit verschijnsel zie O. Bakker, Bedrijfshuishoudkunde, deel II.

m a b blz. 52 
worden vermeden, welk voordeel in onze tijd van voortdurende inflatie, waarin elke gulden teveel in kas, tot onnodige verliezen aanleiding geeft, bijzonder spreekt. $\mathrm{Bij}$ de harmonische diversiteit worden verliezen, welke haar oorsprong vinden in niet voor vervanging besteed schijninkomen, geheel vermeden. Dit valt gemakkelijk in te zien. In elke periode komt voldoende schijninkomen vrij om een nieuw werktuig aan te schaffen, of om een afdeling te vernieuwen. Deze aanschaffingen zullen bij stijgend prijsniveau duurder worden, doch niettemin ontstaat geen vermogensgebrek, daar het schijninkomen eveneens met het stijgend prijsniveau omhoog gaat.

Het werktuigenpark blijft ook bij stijgend prijsniveau op peil. In ons voorbeeld zullen steeds tien werktuigen ter beschikking zijn, en zal de voorraad werkeenheden op vijf en vijftig gehandhaafd blijven, en hoe ook de caprioles van de prijzen zullen zijn, steeds zullen schijninkomen en vervanging aan elkaar gelijk zijn 4). Verliezen kunnen eerst ontstaan indien men de vervanging gaat uitstellen. Hoe meer men het principe: Vervangen op het moment van de ruil nastreeft, hoe meer het ideaal wordt benaderd en hoe minder het risico van inflatieverliezen zal zijn.

Zoals wij reeds hebben aangestipt is de harmonische diversiteit een in de werkelijkheid veel voorkomend verschijnsel, doch het zou bepaald een eenzijdige belichting van de werkelijkheid zijn indien we onze beschouwing tot deze casus beperkten. Als tegenhanger van de casus der harmonische diversiteit stellen we thans de casus dat het vaste goed slechts één werktuig omvat. In ons schema van een paar bladzijden terug waren er tien werktuigen. Wanneer we uit dit schema één kolom nemen hebben we een papieren voorstelling van de situatie zoals we die thans gaan bezien. Er is een maximum vermogensbehoefte bij de aanschaffing van het actief en een minimum vlak vóór de remplacering. In de industrie komen dergelijke gevallen niet zuiver voor, daar er meestal tegelijk een werktuigenpark van een de harmonische min of meer benaderende diversiteit aanwezig is; daardoor ontstaat een vermenging van gevallen. Voorbeelden: de rotatiepers in een drukkerij, een electrische centrale met één agregaat. Het zuiverst komt onze tweede casus wellicht voor in de flatbouw. Men kan zich ook in de werkelijkheid heel goed een onderneming voorstellen die één flatgebouw (woon- of industrieflat) exploiteert, een soort ondernemingen, die men steeds veelvuldiger ziet verschijnen. Wanneer op erfpacht wordt gebouwd ziet men het schema vrijwel feilloos gerealiseerd.

Laten we het geval daarom aan de hand van een flatgebouw bespreken. Dan zullen we tegelijk de cijfers en aantallen uit ons vorige schema daaraan aanpassen en voor de variatie eens niet in werkeenheden spreken, doch in geld.

We nemen aan dat ons flatgebouw $f 1.000 .000$. - kost en vijftig jaar meegaat. Het jaarlijks schijninkomen is dus $f 20.000,-$.

De behoefte aan vermogen wisselt van $f 1.000 .000$, - bij de stichting tot nihil op het moment van de sloop. Het ligt voor de hand dat de financiering moet plaats hebben met afstootbaar vermogen, en wel zodanig dat elk kwotum schijninkomen onmiddellijk weer kan worden afgestoten, dus voor de aflossing kan worden gebruikt. Elke andere financieringswijze is irrationeel, daar dit tot renteverspilling leidt.

Dit is heel gemakkelijk aan te tonen. Laten we aannemen dat het op te nemen vermogen $5 \%$ rente kost. Indien men permanent vermogen aantrekt kost dit gedurende de levensduur van het flatgebouw vijftig maal

4) Hier wordt ook op gewezen door A. I. Diepenhorst in M.A.B. 1955 pag. 399/400. 
$f 50.000,-$ of $f 2.500 .000,-$. In het geval het schijninkomen voor aflossing kan worden gebruikt wordt de totale rentelast $f$ 1.275.000, - (bij aflossing aan het eind van het jaar), dus slechts iets meer dan de helft. Het renteverschil van de beide financieringswijzen kan wel verminderd worden indien men het schijninkomen gaat beleggen, doch het verschil kan nimmer tot nihil gereduceerd worden daar men moet aannemen dat de renteopbrengst altijd kleiner zal zijn dan het percentage hetwelk men moet betalen. $\mathrm{Er}_{\mathrm{r}}$ is daarom slechts één rationele wijze van financiering denkbaar en wel die, waarbij het vermogen nauwkeurig aan de vermogensbehoefte is aangepast.

Dus aflosbaar vermogen, b.v. in de vorm van een obligatielening of onderhandse lening.

Nadat het object al zijn werkeenheden zal hebben afgegeven en het schijninkomen voor aflossing is gebruikt, is het aflosbaar vermogen geheel verdwenen. Onze ondernemer staat er precies zo voor als toen hij zijn onderneming begon, hij is noch rijker, noch armer geworden. Evenals toen moet hij trachten zich op de vermogensmarkt de financieringsmiddelen voor een nieuw flatgebouw te verschaffen.

Een wezenlijke vraag is of er voor de herbouw vermogen beschikbaar is. Dat is er inderdaad, en wel, en daar komt het hier op aan, zonder dat besparingen plaats vinden.

Om deze stelling te argumenteren moeten we onze lezers meenemen op een pad dat hem in de aanvang wellicht vreemd zal lijken. We beginnen met te veronderstellen dat een onderneming vijftig flatgebouwen bezit en wel zo samengesteld dat in elk jaar één flatgebouw geremplaceerd wordt. We hebben hier dus de harmonische diversiteit weer terug. Het in die vijftig flatgebouwen geinvesteerd vermogen is $f 25.500 .000,-$ dus $2 \%$ meer dan de helft van de nieuwprijs van vijftig flatgebouwen. Elk jaar komt vijftig maal $f$ 20.000, - aan schijninkomen binnen, hetwelk besteed wordt voor de stichting van een nieuw flatgebouw, waardoor het aantal flatgebouwen op peil blijft.

$\mathrm{Nu}$ nemen we een schaar en knippen het schema, waarop we onze mammoetonderneming met de harmonische diversiteit op de wijze als op pag. 51 hebben weergegeven, in vijftig kolommen, die we netjes naast elkaar laten liggen. In plaats van één onderneming met harmonische diversiteit stelt ons schema nu voor een complex van vijftig ondernemingen, die wel tezamen een harmonische diversiteit tonen, doch elk afzonderlijk voldoen aan ons tweede schema. Tezamen hebben ze een constante vermogensbehoefte van $f$ 25.500.000, - , doch elk afzonderlijk hebben ze een vermogensbehoefte van maximaal $f 1.000 .000$, - en minimaal nihil.

Van onze vijftig ondernemingen tezamen komt elk jaar vijftig maal $f 20.000$, - of $f 1.000 .000$, - an schijninkomen vrij, hetwelk via aflossing of op andere wijze op de vermogensmarkt wordt aangeboden, terwijl een der ondernemingen een bedrag van $f 1.000 .000$, - voor de stichting van een nieuwe flat nodig heeft, en voor dit bedrag als vrager op de markt verschijnt.

In wezen gebeurt hetzelfde als bij onze mammoetonderneming. Deze laatste behoeft evenwel het door haar benodigde vermogen niet op de markt te vragen, daar zij het eigen gekweekt schijninkomen ter beschikking heeft. De afzonderlijke flatgebouwondernemingen moeten op de vermogensmarkt het van de andere flatgebouwen afkomstige schijninkomen opvangen. In het eerste geval heeft de remplacering door interne financiering plaats in het tweede geval door externe. Tussen haakjes worde hier

m a b blz. 54 
opgemerkt dat de onderneming met interne financiering in het voordeel is, daar het vermogensmarktverkeer kosten met zich brengt, welke bij interne financiering bespaard blijven.

Wat wij met deze redenering duidelijk hebben willen maken is dat de financiering van de remplacering niet plaats vindt uit besparingen, doch uit schijninkomen, zij het schijninkomen dat elders gekweekt kan zijn.

We gaan thans in onze veronderstelling een prijsstijging invoeren. Op wat voor wijze die prijsstijging verloopt is voor de behandeling van ons onderwerp onverschillig, doch om de gedachte te bepalen veronderstellen we een voortschrijdende prijsstijging van $2 \%$ per jaar, zodat na 50 jaar de prijzen verdubbeld zijn. Dit heeft o.m. de volgende gevolgen:

1e. het schijninkomen stijgt elk jaar met $f 400,-(2 \%$ van $f 20.000,-$ ) tot het laatste jaar een maximum van $f 40.000,-$ is bereikt;

2e. voor de remplacering van het flatgebouw is het dubbele nodig van het oorspronkelijke bedrag, dus $f$ 2.000.000, -

We gaan nu dezelfde redenering volgen als toen de prijzen gelijk bleven. We veronderstellen dus eerst een onderneming die vijftig flatgebouwen bezit die in opeenvolgende perioden slooprijp worden en geremplaceerd moeten worden. We krijgen dan een situatie die in principe gelijk is aan die van onze eerste casus bij stijgende prijzen. Binnen de onderneming worden voldoende middelen, in de vorm van schijninkomen, gekweekt om in elke periode een flatgebouw te remplaceren, tegen voortdurend stijgende prijzen. Na een jaar kost een nieuw flatgebouw f 1.020 .000 , - , doch het schijninkomen is eveneens tot dit bedrag gestegen. $\mathrm{Na}$ vijftig jaar moet $f$ 2.000.000, - voor een flatgebouw worden uitgegeven, doch het schijninkomen is even groot. Behalve het in de onderneming gestoken bedrag van $f 25.500 .000$. - is geen verdere toevoeging van vermogen nodig, noch van buitenaf, noch uit de winst. Reserveringen zijn niet nodig. De nieuwbouw bij gestegen prijsniveau wordt dus geheel uit schijninkomen gefinancierd zonder dat besparingen nodig zijn.

Wanneer wij thans weer het (niet weergegeven, doch aan de fantasie van de lezer overgelaten) schema in vijftig kolommen knippen, die we precies zo laten liggen als toen het schema nog intact was, hebben we weer de voorstelling van vijftig afzonderlijke flatgebouwondernemingen. Elk afzonderlijk flatgebouw kweekt in elke periode een zeker schijninkomen dat evenredig met de stijging van het prijsniveau omhoog gaat. Een van de ondernemingen moet zijn flatgebouw remplaceren, en heeft daarvoor een bedrag nodig dat juist gelijk is aan de vijftig schijninkomens waarvan er een in zijn eigen onderneming gekweekt is. Hij mist de negen en veertig andere en treedt daarvoor als vrager op de vermogensmarkt op. De overige negen en veertig ondernemingen bieden hun schijninkomen op de vermogensmarkt aan, dan wel komt het via aflossing op de vermogensmarkt. In de volgende periode is weer een andere onderneming aan de beurt en hetzelfde vraag - en aanbodspel herhaalt zich.

We zien hier dus weer dat het vermogen voor remplacering van een flatgebouw beschikbaar is, en wel zonder dat besparingen plaats vinden. De vijftig flatgebouwen tezamen redden zich met het oorspronkelijke vermogen van $f 25.500 .000,-$, zonder dat verdere toevoeging uit besparingen of reserveringen nodig is.

De aandachtige lezer zal hebben bemerkt dat een bepaalde feature van de werkelijkheid in het bovenstaande buiten beschouwing gebleven is, en 
wel de juridische vorm, waarin de geschetste vermogensovergangen plaats vinden. Deze speelden geen rol in onze redenering, doch in de werkelijkheid kan men het vraagstuk niet omzeilen.

De juridische verhouding ten opzichte van een vermogen waarover men de beschikking heeft kan twee vormen aannemen

le. eigendom van de onderneming;

2e. geleend, eigendom van derden.

De betekenis van de juridische vorm heeft verschillende aspecten. Voor ons is van belang dat geleend vermogen in het algemeen terugbetaald moet worden niet met de waarde die het had ten tijde van het verstrekken der lening, doch met het nominale bedrag. De pogingen om met goud- of valutaclausules hierin wijziging te brengen heeft geen grote verbreiding gevonden. Wellicht dat het vooruitzicht van permanente inflatie de verschaffers van vermogen ertoe brengen $z a l$, te trachten voor geldleningen op lange termijn een indexcijferclausule te vestigen, hetgeen zou medebrengen dat het terug te betalen nominale bedrag verhoogd wordt aan de hand van een ten tijde der terugbetaling geldend indexcijfer.

Wij hebben betoogd dat het economisch motief meebrengt dat de financiering van een afzonderlijk flatgebouw geschiedt met aflosbaar, dus geleend, vermogen, hetwelk uit het schijninkomen wordt terugbetaald. Indien het prijsniveau stijgt ontstaat er een verschil tussen schijninkomen en nominaal vermogen, hetzij, indien per periode slechts de nominale kwote wordt afgelost, een periodiek overschot, hetzij, indien het gehele schijninkomen voor aflossing wordt gebruikt (vanzelfsprekend het meest economische), nadat het laatste deel van het geleend vermogen is terugbetaald. Onze flatgebouwonderneming gaat dus een overschot kweken, gaat winst maken; geen „,bedrijfswinst", d.i. een overschot van opbrengsten boven kosten, doch ,inflatiewinst". Dit is in overeenstemming met het algemeen waarneembaar verschijnsel dat bij stijgend prijsniveau de schuldenaar van nominaal vermogen ,,winst" maakt, hetwelk gelijk is aan het ,verlies" dat door de eigenaar van het vermogen wordt geleden. Deze lijdt wel geen verlies in nominaal vermogen, doch wel in waarde: zijn claim op het maatschappelijk goederenfonds is gedeprecieerd. Veranderingen in prijsniveau brengen dus verschuivingen met zich; de ene wordt rijker en de ander armer.

Dat onze ondernemer inderdaad rijker wordt blijkt uit het feit dat hij ten tijde van het remplaceren van zijn flatgebouw over enig eigen vermogen beschikt, en dus een deel van het flatgebouw zelf kan financieren. Toen hij zijn eerste flatgebouw neerzette, moest hij het volledig benodigde vermogen lenen, de tweede maal behoeft hij slechts een deel van het benodigde vermogen te lenen.

Wij zullen trachten het gegeven beeld van onze combinatie van flatgebouwondernemingen uit het oogpunt van de depreciatie van het nominaal vermogen, nog iets nader te adstrueren. Laten we veronderstellen dat er één geldschieter is voor alle 50 flatgebouwen.

Deze geldschieter heeft aan alle flatgebouwen het door deze benodigde vermogen geleend. Het schijninkomen ontvangt hij als aflossing en hij geeft de daarvoor hem ter beschikking komende gelden door aan de onderneming die aan remplacering toe is.

Vóór de prijsstijging kon deze geldschieter met een bedrag van f 25.500.000, - alle flatgebouwen financieren, doch zodra prijsstijging optreedt wordt dit vermogen onvoldoende. Hij ontvangt zijn jaarlijkse aflos-

$\mathrm{mab}$ blz. 56 
singen tot een totaal bedrag van $f 1.000 .000, \ldots$, doch er is méér nodig dan dit bedrag voor de stichting van een nieuw gebouw. Wij hebben reeds gezien dat de flatgebouwondernemingen overschotten kweken doordat het schijninkomen de aflossingsverplichting te boven gaat. Deze overschotten kunnen zij aan elkaar gaan uitienen. Een gevolg is dat naast de financiering door de centrale geldschieter een onderlinge financiering gaat ontstaan. $\mathrm{E}_{\mathrm{r}}$ ontstaat geen vermogenstekort, doch het aandeel van de centrale geld schieter in de vermogensverschaffing wordt kleiner.

$\mathrm{Nu}$ gaan we veronderstellen dat onze centrale geldschieter bedongen heeft dat de terugbetalingen zullen plaats hebben op basis van een indexcijfer zodanig dat de aflossingen evenredig met het prijsniveau stijgen. Onze centrale geldschieter ontvangt nu weer onverminderd alle schijninkomens welke per periode tezamen voldoende zijn voor de financiering van één flatgebouw ook bij gestegen prijsniveau.

De centrale geldschieter ontvangt op de geschetste wijze het volledige schijninkomen; de financiering van de vijftig flatgebouwen blijft volledig in zijn handen.

Op het zuiver economisch (bedrijfseconomisch) deel van ons vraagstuk heeft dit verschuivingsverschijnsel geen invloed. Het schijninkomen wordt voorzover het voor aflossing wordt besteed door de eigenaar van het vermogen opnieuw op de vermogensmarkt aangeboden. Het overschot van het schijninkomen boven de nominale aflossingsverplichting wordt door de flatgebouwonderneming zelf op de vermogensmarkt aangeboden. Het totale vermogensaanbod is dus gelijk aan het totale schijninkomen. De ju ridische verhoudingen veroorzaken dus geen storing in de economische verschijnselen, doch beperken zich tot verschuivingen in de persoonlijke rechten op het maatschappelijke goederenfonds.

De lezer zal zich afvragen in hoeverre de hier gebezigde gedachtenconstructie in de practijk haar weerspiegeling vindt. Het zou onjuist zijn aan de gedachtegang practische gevolgtrekkingen te verbinden indien ze in de werkelijkheid niet zou zijn gerealiseerd.

In de werkelijkheid zullen we onze beide casus natuurlijk nimmer zuiver aantreffen. Steeds zal er een combinatie zijn. Deze combinaties zijn evenwel voor onze redenering bereikbaar. Wanneer we een werktuig met zijn remplacering een staaf noemen, dan bestond onze eerste casus uit tien staven en onze tweede uit één staaf. In de werkelijkheid zullen zich gevallen voordoen waarbij de bedrijven over een aantal staven beschikken liggend tussen of boven deze twee besproken gevallen, b.v. twee of vijf of twaalf.

De vermogensbehoefte bij tien staven was voor onze eerste casus constant. In het geval er één staaf is schommelt de vermogensbehoefte van een maximum tot nihil. In de tussenliggende gevallen ligt de vermogensbehoefte tussen deze uitersten in met dien verstande dat het maximum altijd minder is dan het aantal staven maal de nieuwprijs en het minimum altijd hoger dan nihil. Een factor die hier meespeelt is hoe de verhouding van de staven ten opzichte van elkaar is. Indien de staven 10 jaar meegaan en er drie aanwezig zijn dan kan de remplacering plaats hebben na één, één en acht jaar, doch ook na twee, twee en zes jaar, na drie, drie en vier jaar, en zo zijn er nog meer combinaties denkbaar. Ingeval er twee staven zijn die na een en negen jaar worden geremplaceerd is de maximum vermogensbehoefte gelijk aan het schijninkomen van één werktuig in één periode. Ingeval er drie werktuigen zijn met remplacering na een, een en acht jaar, is de 
minimum vermogensbehoefte gelijk aan het schijninkomen van drie perioden. Ingeval van vier werktuigen met remplacering na een, een, een en zeven perioden is de minimum vermogensbehoefte gelijk aan zes van dergelijke schijninkomens enz. Ter vermijding van misverstand zij opgemerkt dat een groep van werktuigen die gelijk geremplaceerd moeten worden en een even lange levensduur hebben, tezamen één staaf vormen.

Indien er méér werktuigen zijn dan met de harmonische diversiteit overeenkomt is er een combinatie van twee gevallen. Een deel van het bedrijf valt onder het geval van de harmonische diversiteit en een ander deel omvat een of meer staven zonder dat er volledige harmonische diversiteit is.

Onder bovenstaande redenering zal wel het overgrote deel der in de practijk voorkomende gevallen te rangschikken zijn. Vermoedelijk zou bij een enquete blijken dat de harmonische diversiteit een veelvuldig voorkomend verschijnsel is en bovendien een verschijnsel dat relatief toeneemt. Het feit dat de gevallen van harmonische diversiteit minder vermogen eisen zal een bijdrage leveren die de ondernemer in deze richting drijft. Een andere kracht die in dezelfde richting werkzaam is is de groei van de bedrijven. Hoe groter een bedrijf is, des te groter is de kans dat in het bedrijf harmonische diversiteit voorkomt; hierbij verwijzen wij naar onze vroegere opmerking dat de harmonische diversiteit niet beperkt is tot werktuigen van gelijke soort, doch dat $z \mathrm{ij}$ ook door een groep afdelingen kan worden bereikt. Ook door werktuigen van verschillende levensduur kan harmonische diversiteit ontstaan. Eigenlijk is de harmonische diversiteit steeds daar aanwezig indien het beschikbaar komende schijninkomen onmiddellijk voor vervanging werd gebruikt.

In de practijk doen zich hier storingen voor, wanneer n.l. de remplacering wordt uitgesteld. Uitstel van de remplacering is technisch mogelijk doordat een werktuig ook nadat het versleten is meestal toch nog meekan in die zin dat het zijn technische bijdrage aan de productie kan leveren, $z$ ij het met dergelijke bijkomende complementaire kosten dat van een schijninkomen geen sprake meer kan zijn. Fouten in de financiering, schaarste e.a. kunnen oorzaak zijn dat de ondernemer in zulk een geval toch niet tot remplacering overgaat en daardoor een doorbreking van de harmonische diversiteit veroorzaakt.

Bekeken we tot nu toe de toepassing op de afzonderlijke bedrijven, we mogen niet nalaten na te gaan of de onderstelling dat er voldoende schijninkomen op de markt komt, om de bedrijven die zichzelf niet aan voldoende schijninkomen kunnen helpen, met de werkelijkheid overeenkomt. Het is niet moeilijk in te zien dat er voldoende schijninkomen gekweekt wordt. Immers vrijwel elk werktuig dat meedoet aan de productie levert schijninkomen op, welk schijninkomen voorzover het niet in het betreffende bedrijf zelve wordt gebruikt op de een of andere wijze op de markt komt. Hetzij dat het voor aflossing van schuld dient, dan biedt de eigenaar van het vermogen het opnieuw aan; hetzij dat het vermogen eigendom van het bedrijf is hetwelk het schijninkomen kweekte, dan biedt dit bedrijf het op de vermogensmarkt aan; dan wel dat het bedrijf voor een kleiner bedrag dan voorheen als vrager optreedt (neemt b.v. minder bankcrediet of leverancierscrediet $o p$ ). We kunnen dus wel inzien dat het schijninkomen dat niet in het bedrijf zelf voor vervanging wordt gebruikt direct of indirect op de markt komt en tenzij storingen optreden (die buiten het bestek van dit artikel gaan) ook ter beschikking komen van vragers naar vermogen die dat voor remplacering nodig hebben. 
Het komt ons voor dat wij voor een bepaald soort schijninkomen een uitzondering moeten maken. Vermoedelijk wordt een groot deel van het schijninkomen, dat gekweekt wordt in de niet bedrijfsmatige huizenexploitatie, nimmer op de vermogensmarkt aangeboden, doch wordt voor vertering aangewend. Dit veroorzaakt een verkrapping op de vermogensmarkt, die slechts door besparing kan worden aangevuld. Deze besparing behoeft niet te komen van het bedrijf dat behoefte aan vermogen heeft, doch kan ook komen van anderen.

En nu de kwestie van de boeking.

In de boekhouding werken we niet met het begrip schijninkomen, doch met het parallelbegrip afschrijving. De afschrijving is het middel waardoor het schijninkomen uit het totale inkomen wordt afgezonderd. (Ter vermijding van misverstand zij opgemerkt dat de afschrijving mede moet omvatten de werkeenheden welke door onderbezetting of verspilling verloren gaan).

Het valt niet in te zien dat wanneer de input van een onderneming gelijk is aan de output, d.w.z. dat voor alles wat de onderneming verlaat de volle tegenwaarde binnenkomt, er verliezen geleden zouden worden. En dit wordt toch implicite beweerd door die schrijvers die de stelling verkondigen dat bij prijsstijging van bedrijfsmiddelen bovendien nog verliezen geleden worden op de vroeger plaats gehad hebbende afschrijvingen. Deze stelling kan onmogelijk juist zijn en wanneer geen verliezen ontstaan behoeven ook geen desbetreffende boekingen plaats te hebben.

\section{Verliezen kunnen slechts ontstaan:}

a. indien hetgeen de onderneming verlaat meer is dan wat er in komt (afstoten beneden kostprijs, verspillingen);

b. waardedaling van activa minus passiva, welke in de devaluerende valuta luiden;

c. prijsdalingen van activa in de goederensfeer, en in vreemde valuta.

Niet wordt ontkend dat er verliezen kunnen plaats hebben, wanneer men het vroeger gevloeide schijn-inkomen in kas heeft bewaard. In dat geval zal dit tezamen met de latere afschrijvingen niet voldoende opleveren om een nieuwe machine te kopen. Dit soort verlies valt onder bovengenoemde groep b. Doch het bewaren van gelden in de onderneming is irrationeel. De gelden uit schijninkomen afkomstig moeten of voor vervanging of voor aflossing worden aangewend. In beide gevallen worden verliezen vermeden.

De conclusie moet dus luiden dat de door de betreffende schrijvers bedoelde verliezen slechts kunnen ontstaan door financieringsfouten.

\section{Litteratuur.}

De door mij bestreden opvattingen zijn te vinden bij:

Th. Limperg: De gevolgen van de depreciatie van de gulden voor de berekening van waarde en winst. 25 jaren M.A.B. I pag. $344 / 5$.

H. J. van der Schroeff: De leet van de kostprijs, le druk pag. 153

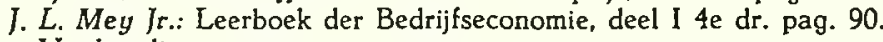

Verdere litteratuur:

N. J. Polak: Enige grondslagen voor de financiering van de onderneming.

$S$. $A$. de Vries: De waardering van duurzame productiemiddelen in verband met wijziging van het prijsniveau. M.A.B. 1949 pag. 66.

L. F. Ras: De diversiteitsfactor en de toepassing van de vervangingswaarde bij duurzame productiemiddelen. M.A.B. 1950 pag. 53.

J. de Jong: Vervangingswaarde en balanspolitiek. M.A.B. 1946 pag. 346 en 1947 pag. 4.

B. Pruyt: Diesrede November 1954.

A. I. Diepenhorst: Een bedrijfseconomisch model voor de problemen van waarde en winst. M.A.B. 1955 pag. 399/400.

m a b blz. 59 